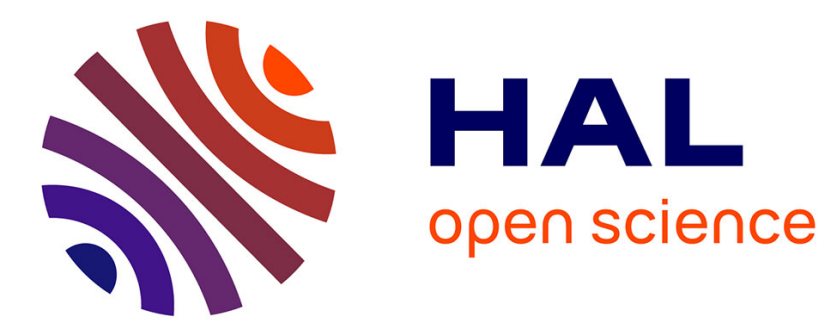

\title{
Personality, Affectivity, and Alexithymia in Scuba Diving: Two Types of Risk Taking
}

\author{
Agnès Bonnet-Suard, Vincent Bréjard, Jean-Louis Pedinielli
}

\section{To cite this version:}

Agnès Bonnet-Suard, Vincent Bréjard, Jean-Louis Pedinielli. Personality, Affectivity, and Alexithymia in Scuba Diving: Two Types of Risk Taking. Journal of Clinical Sport Psychology, 2017, 11 (3), pp.254 - 270. 10.1123/jcsp.2014-0049 . hal-02087541

\section{HAL Id: hal-02087541 https://hal-amu.archives-ouvertes.fr/hal-02087541}

Submitted on 2 Apr 2019

HAL is a multi-disciplinary open access archive for the deposit and dissemination of scientific research documents, whether they are published or not. The documents may come from teaching and research institutions in France or abroad, or from public or private research centers.
L'archive ouverte pluridisciplinaire HAL, est destinée au dépôt et à la diffusion de documents scientifiques de niveau recherche, publiés ou non, émanant des établissements d'enseignement et de recherche français ou étrangers, des laboratoires publics ou privés. 


\title{
Personality, Affectivity, and Alexithymia in Scuba Diving: Two Types of Risk Taking
}

\author{
Agnès Bonnet \\ Université de Lyon \\ Vincent Bréjard and Jean-Louis Pedinielli \\ Aix-Marseille Université
}

\begin{abstract}
Objectives for this study were, first, to describe individual differences in risk taking among scuba divers. Differences were examined on personality dimensions and psycho-affective variables, including positive and negative affect, as well as alexithymia. In addition, the study examined contributors to two types of behavior associated with scuba diving-deliberate risk taking and controlled participation in a high-risk sport (non-risk-taking). A cross-sectional design was used, and 131 participants were assessed on extraversion-neuroticism, affectivity, and alexithymia. The broad dimensions of personality and affectivity explained risk taking among divers. Alexithymia differentially predicted two types of risktaking behavior (direct or short-term and indirect or long-term) and was associated significantly with short-term risk-taking behavior.
\end{abstract}

Keywords: risk-taking behavior, extraversion, emotion regulation

Sport-related injury is considered a global health problem, and risk-taking behavior has been closely associated with injury in young adult athletes (Green, Turner, Purdie, \& McClure, 2003). Changes in perception of risk occur over time with scuba divers, and confidence, in part, contributes to risk taking and related accidents in experienced divers (Morgan \& Stevens, 2008). In France, about 350 accidents occur every year in scuba diving, with the majority involving experienced male participants (Coulange et al., 2013; Grandjean, 2010). The most frequent injuries associated with diving procedural error are spinal cord injuries, other acute neurological conditions, and pulmonary edema (Boden, 2008). Risk taking in performance and competition have been identified as major risk factors for these injuries (Lefevre \& Elfeki-Mhiri, 2015).

Within the last few years, high-risk sports—-such as skydiving, surfing, and scuba diving - have enjoyed growing popularity in Western countries (Jones,

Bonnet is with the Université de Lyon, Lyon, France. Bréjard and Pedinielli are with the Aix-Marseille Université, Marseille, France. Please address author correspondence to Agnès Bonnet at Agnes.BonnetSuard@univ-lyon2.fr 
Asghar, \& Llewellyn, 2007; Merritt \& Tharp, 2013). It is important to consider the modes of participation these sports involve and the different strategies used by athletes who engage in them. Some researchers have distinguished between "high risk-takers" and "extreme risk-takers" (Llewellyn, Sanchez, Asghar, \& Jones, 2008; Slanger \& Rudestam, 1997). The literature concerning individual differences among participants in high-risk sports, however, remains incomplete (Jack \& Ronan, 1998; Tok, 2011).

High-risk sports involve potential injury or death, and they require special equipment to minimize the risk level. Participants in these sports are generally thought to be sensation-seekers (Castanier, Le Scanff, \& Woodman, 2011; Ferrando \& Chico, 2001; Zuckerman, 2007). If we examine the context of these sports in greater detail, however, two types of participants emerge: those who deliberately put themselves in dangerous situations, and those who work to reduce the risks related to their sport (Slanger \& Rudestam, 1997). Indeed, not all participants in extreme sports can be considered deliberate risk-takers; some do not directly seek risk for themselves but rather try to control it.

\section{Risk Taking in Sport}

Not all risk taking involves danger seeking, although danger is ever present in risky activities. Sport engagement considered risky behavior by Adès and colleagues (1994) involve the choice of dangerous activities. Athletes may make these choices because their technical mastery and expertise permit them to do so, but they may also attempt to reduce their risk. Adès and colleagues define risk as life-threatening dangers (e.g., risk of an accident, violent death). The factors motivating an athlete's behavior may allow us to differentiate simple participation in a risky sport activity from risk-taking behavior in that activity (e.g., failing to consider the consequences of one's actions, underestimating danger). One can also distinguish between different forms of risk taking according to whether the activity involves direct (short-term) or indirect (long-term or delayed) exposure to danger (Bonnet, Fernandez, Piolat \& Pedinielli, 2008; Michel, Purper-Ouakil, \& Mouren-Siméoni, 2002).

In scuba diving, the risks are defined by the medical consequences of the behavior. Several physiological mechanisms (biomechanical, biochemical, or biophysical) can be the source of accidents. Biomechanical accidents (related to pressure variations) occur rarely among experienced divers; such accidents are most often linked to the diver's lack of technical mastery. Biochemical and biophysical accidents (linked to partial changes in the pressure of the gas being breathed and the elimination of nitrogen) may result from the practices of experienced divers and are a major problem for divers who deliberately take risks.

Previous studies have explored individual differences as potential differentiators between participants in risky sports and non-risk-taking controls (Fave, Bassi, \& Massimini, 2003). These studies have assumed homogeneity within high-risk groups (Llewellyn \& Sanchez, 2008). Zuckerman's (1984, 2007) theory of sensation seeking offered a behavioral and biological model of personality to explain why certain individuals participate in risky activities or sports. Sensation-seeking levels are associated with certain biological processes, such as neuroendocrine systems (Netter, Hennig, \& Roed, 1996; Roberti, 2004). Activities must be a source of 
arousal for the sensation seeker, and high-risk sports may serve simply as a means for individuals to achieve increased levels of arousal (Freixanet, 1991; Roberti, 2004). While sensation seeking may provide a partial explanation for risk-taking behavior, it is worth noting that behaviors typically serve many different goals and functions (Castanier, Le Scanff, \& Woodman, 2011).

In psychopathology, risk-taking behavior cannot be defined by the objectivity of the risk, nor by its gravity. To distinguish between risk taking related to danger seeking and mere participation in a risky activity (Merritt \& Tharp, 2013), the subject's personality traits and the function of the behavior must be taken into account. Sensation seeking has been related to factors in the Big Five (openness, conscientiousness, extraversion, agreeableness, and neuroticism; Costa \& McCrae, 1992) personality models (Aluja, Garcia, \& Garcia, 2002; Glicksohn \& Abulafia, 1998). For example, thrill and adventure seeking have been related to extraversion. Some studies have even identified a personality "profile" that characterizes individuals who participate in high physical-risk sports; it includes traits such as sensation seeking, danger seeking, and disinhibition, as well as extraversion and neuroticism (Freixanet, 1999; Zuckerman, 2007).

Neuroticism (emotional instability) and extraversion have been considered representative of the basic dimensions of temperament, which broadly reflect individual differences in the propensity to experience negative and positive affect, respectively (Eysenck, 1967; Tellegen \& Waller, 2008). An extraverted subject is sociable, lively, active, assertive, and sensation seeking; he or she is carefree, dominant, restless, and adventurous. A subject who has high scores on neuroticism is emotionally unstable, anxious, depressed, shy, or vulnerable, and may also be impulsive and angry. The association between personality and risk taking has often been investigated by exploring the extent to which the dimensions of the five-factor model are related to risk taking in different domains (Nicholson, Soame, Fenton-O'Creevy, \& Willman, 2005). Merritt \& Tharp (2013) showed that, unlike extraversion, neuroticism is an important variable in risk taking in extreme sports. Moreover, Castanier, Le Scanff, and Woodman (2010) showed that personality was a significant predictor of risk taking and that low awareness associated with high extraversion and/or high neuroticism could predict risk taking. The positive association between extraversion and risk taking has been found in numerous studies. However, these studies did not take into account relationships between personality type, subtraits (such as impulsiveness), and the affective dimensions (positive and negative affect, anxiety, depression), which could interact in determining risk taking. Interactions among these variables could explain why extraversion can either increase or decrease risky behavior, depending on the individual and context (Castanier, Le Scanff, \& Woodman, 2010).

Temperament researchers have begun examination of the psycho-affective components of risk-taking behavior and the links between these behaviors and emotion regulation (Bonnet, Fernandez, Piolat, \& Pedinielli, 2008). Due to its association with neuroticism (David, Green, Martin, \& Suls, 1997), affectivity (particularly when it is negative) has been seen primarily as a contributor to risky behavior (Auerbach, Abela, \& Ho, 2007; Cooper, Agocha, \& Sheldon, 2000). Affectivity modulates an individual's sensitivity for experiencing certain emotional states along two affective dimensions, positive affectivity (PA) and negative affectivity (NA), which Larsen referred to using the term emotionality (Larsen \& Diener, 1985). 
Evidence supporting this dimensional conception has been obtained from several questionnaires, including the Positive and Negative Affective States Scale (PANAS; Watson \& Clark, 1984), the Mood and Anxiety Symptom Questionnaire (MASQ; Watson et al., 1995), and the Positive and Negative Emotionality Scale (EPN-31; Pelissolo, Rolland, Perez-Diaz, Jouvent, \& Allilaire, 2007). Positive emotionality and negative emotionality are dimensions of temperament that contribute to individual differences in the experience of predominantly positive or negative affect (Rothbart \& Bates, 1996). These dimensions are regarded as distinct constructs by personality theorists (Diener \& Larsen, 1993). Negative emotionality is often defined as proneness to seek the experience of negative emotions and psychological distress. In studies dealing with risky behavior, negative emotionality is often associated with emotional distress and symptoms of depression (Buckner, Keough, \& Schmidt, 2007; Cranford, Eisenberg, \& Serras, 2009; Magid, Colder, Stroud, Nichter, \& Nichter, 2009). Numerous studies have found a significant relationship between the frequency of risk taking, including substance use disorders, and impulsive behaviors, and the propensity to experience negative emotional states. Individuals who exhibit deficits in emotion-regulation strategies appear to be more prone to risky behaviors, which they may use as a means of avoiding negative affect (Cicchetti, Ackerman, \& Izard, 1995; Cooper, Agocha, \& Sheldon, 2000).

In the domain of emotions, the dynamics of the relationships between neuroticism, extraversion, and alexithymia also have been explored (Pandey \& Mandal, 1996). Alexithymia, or inability to describe one's emotional experience, has been positively correlated with neuroticism and perceived autonomic arousal, and negatively correlated with extraversion (Bagby, Taylor, \& Parker, 1994; Wise, Mann, \& Shay, 1992). Extraversion also exhibits a positive correlation with the expression of positive emotions, whereas neuroticism is associated with the expression of negative emotions (Gross, 1999). Unlike introverted subjects, extraverted and emotionally unstable subjects appear to be able to express their emotions, whatever the valence. Alexithymia has been characterized as a specific mode of emotional functioning (Sifneos,1973), which may be primary (of neuropsychological origin) or secondary and adaptive (Myers, 1995; Tabibnia \& Zaidel, 2005). Secondary alexithymia refers to a dimension of personality that accounts, in particular, for relationships between temperamental emotional instability (neuroticism) and certain psychopathological disorders (Luminet, Bagby, Wagner, Taylor, \& Parker, 1999; Zimmermann, Rossier, Stadelhofen, \& Gaillard, 2005). Some researchers, however, contend that there is no structural difference between primary and secondary alexithymia, since both pertain to the same inability to use cognition to identify emotions and to make use of them in interacting with the surrounding environment (Corcos \& Speranza, 2003).

In either case, alexithymia corresponds to a particular mode of emotion processing, characterized by deficient mental representations of subjective experience (Sifneos, 1973). It is said to have both a cognitive and an emotional component (Loas, Otmani, Lecercle, \& Jouvent, 2000). The cognitive component refers to the person's preoccupation with the factual and objective characteristics of the environment, to the detriment of interest in his/her own subjective states. The emotional component has to do with difficulty identifying one's emotional states and distinguishing them from one's sensations, as well as difficulty expressing them verbally (Loas et al., 2000; Pedinielli, 1992). Alexithymia may be present in various clinical populations, including individuals with diagnoses of posttraumatic 
stress disorder, psychosomatic disorders, and substance use disorders (Pedinielli, 1992). It may be linked to various symptoms (most notably, anxiety) but also to risky behaviors (Ciarrochi, Scott, Deane, \& Heaven, 2003; Honkalampi, Hintikka, Tanskanen, Lehtonen, \& Viinamäki, 2000). A study of substance users showed that alexithymia could be a mediating variable between affectivity and risky behaviors (Bonnet, Bréjard, \& Pedinielli, 2013). In sport, difficulty describing one's emotions has been associated with high-risk activities - for example, rock climbing (Woodman, Cazenave, \& Le Scanff, 2008).

Although both personality, affectivity, and emotionality variables have been associated with risk-taking behavior in sport, no studies have systematically examined the relationship of these variables among participants in a high-risk sport. The main objective of the current study was to describe individual differences in the personality variables (neuroticism/extraversion), psycho-affective variables (positive/negative affectivity), and emotional variables (alexithymia) among scuba divers, according to their mode of participation-that is, risk taking (RT) versus non-risk-taking (NRT) - and to the type of risk taking-that is, short-term (STRT), or direct risk taking, versus long-term (LTRT) or indirect risk taking. The secondary objective was to determine the risk factors for each type of risk-taking behavior (RT/NRT and STRT/LTRT). The analyses were conducted in two stages: stage 1 divided the sample of divers into two groups according to their mode of sport participation (RT/NRT), while stage 2 examined only the risk-taking divers, who were divided into two groups according to their type of risk taking (STRT/LTRT).

\section{Method}

\section{Participants}

The population consisted of 131 scuba divers using air as their breathing mixture, with a gender breakdown of 116 males and 15 females. This ratio is representative of the diving population, since scuba diving is much more common among men than among women. The participants' mean age was $40.20(S D=9.45$, range $=22-70)$.

All divers had reached a diving skill level that enabled them to dive safely without an instructor-level III for the Fédération Française d'Etudes et de Sports Sous-Marins (FFESSM). Their answers to a questionnaire about their diving practices were used to classify them into risk groups. Sixty-one of the divers usually took diving risks (RT) and seventy divers did not (NRT). The risk-takers said that they (a) dove to depths below $65 \mathrm{~m}$, and (b) did not follow safety rules (e.g., several dives in succession with a high time-to-depth ratio, leading to nitrogen saturation). These practices were then labeled (a) short-term risk-taking behavior (STRT, $n=36$ ) or (b) long-term risk-taking behavior (LTRT, $n=25$ ), depending on whether there was direct or indirect confrontation with danger of injury. Risk taking was considered imminent or short term if it involved diving at depths below $65 \mathrm{~m}$, and it was considered delayed or long term if it involved nonobservance of safety rules while diving less than $65 \mathrm{~m}$. Both sets of behaviors were considered forms of risk taking because they can cause a biochemical or biophysical diving accident or death. 


\section{Materials and Procedure}

Risk-Taking Assessment. A 12-item, forced-choice questionnaire was devised to determine eligibility for the study, classify the divers as RT or NRT, and describe their practices in greater detail. The questionnaire assessed a participant's diving level, preferred diving depth, diving frequency, total number of dives performed, abidance by safety rules, and prior accidents. Risk-taking behavior corresponds to usual diving behavior that ignores the legal depth limit $(65 \mathrm{~m})$ or neglects the safety rules with a legal depth.

Eysenck Personality Inventory. Extraversion-introversion (E) and neuroticism (N) were measured on the Eysenck Personality Inventory (EPI; Eysenck \& Eysenck, 1971), where each trait is assessed with 24 items. The inventory also includes an 8-item Lying scale (L). The full inventory thus consists of 57 questions scored on a binary scale $(0,1)$, with participants answering "yes" or "no." There are two versions of the questionnaire, Type A and Type B, which can be used independently. The reliability indexes are satisfactory (test-retest: .80 and .97 for the separate versions, and .74 to .91 for split-half), and the factorial validity is well established (Eysenck, 1967). The French validation of the tool gave rise to values comparable to those obtained for the initial English version (Eysenck \& Eysenck, 1971). We noted an effect of age and gender on both factors. For this study, Cronbach's alpha for $\mathrm{E}$ and $\mathrm{N}$ were .90 and .81 , respectively.

Emotionality. Negative emotionality (NE) and positive emotionality (PE) were assessed using the Emotionality-Positive and Negative scale (EPN-31; Pelissolo, Rolland, Perez-Diaz, Jouvent, \& Allilaire, 2007), which is a Likert-type scale comprising 31 items (score range: 10-70). The factorial structure of the EPN-31 is well established, with a three-factor solution (PE, NE, and emotional arousal or EA) accounting for $58.2 \%$ of the questionnaire variance. The pattern of correlation with anxiety and depression scores is consistent with Watson and Clark's (1995) tripartite model. For this study, Cronbach's alpha values for NE, PE, and EA were $.93, .87$, and .77 , respectively.

Alexithymia. Inability to identify and label emotional experience was assessed on the French version of the 20-item Toronto Alexithymia Scale (TAS-20; Loas et al., 2001). This scale has a three-factor structure: difficulty identifying feelings (DIF), difficulty describing feelings (DDF), and externally oriented thinking (EOT). DIF includes 7 items assessing the ability to identify feelings and distinguish them from the somatic sensations that accompany emotional arousal. DDF consists of 5 items assessing the ability to describe one's feelings to other people, while EOT consists of 8 items assessing externally oriented thinking. The present study used the three-factor subscale scores and a total score summing all three factors. Both the reliability and the validity of the TAS-20 have been amply demonstrated. Internal consistency was good for the total TAS-20 scale (alpha = .79) and for the DIF $($ alpha $=.77)$ and DDF (alpha $=.72)$ subscales, but the internal consistency of the EOT subscale was only moderate $($ alpha $=.61)$. 


\section{Procedure}

Participants were recruited in Marseille, Nice, Toulon, and Perpignan (France), and Geneva (Switzerland). Researchers contacted the large majority of the divers at diving centers through posted notices in diving stores and hospital hyperbaric centers. They administered the questionnaires in person or by mail, depending on risk-taking variables. All participants filled out a questionnaire about their usual diving practices. In doing so, they agreed to participate in the study. The next step was to collect the personality and psycho-affective data, and the procedure for this step differed for risk-taking and non-risk-taking divers. For non-risk-takers, data collection took place at their diving clubs in the presence of the researcher. For the risk-takers, it was not possible from an ethical or legal standpoint for the experimenter to be present during the dive, because risky dives (descent depth greater than $65 \mathrm{~m}$ ) are prohibited in diving clubs. These divers were given paper copies of the questionnaires, with the same instructions as for the non-risk-takers. They were to mail the completed scales to the experimenter.

\section{Results}

The same statistical analyses were performed in each of the two stages of the study. First, descriptive analyses examining potential age- or gender-related differences were conducted. Means were compared by age group and gender using ANOVAs. Correlation analyses (Bravais-Pearson and Spearman's rho for small sample sizes of the subgroups) were then conducted to detect relationships between the different variables in the study. Finally, Wald's step-by-step ascending logistic regression analyses were conducted to calculate the odds ratios (OR) and their $95 \%$ confidence intervals $(95 \% \mathrm{CI})$, and to adjust for potential confounding factors. To be input into the logistic regression, a variable had to meet at least one of the following conditions: (a) have a $p$ value of .20 or smaller in the univariate analysis or (b) constitute a potential risk factor. The OR is an estimate of the increase in the likelihood of engaging in a risky behavior (and a short-term risky behavior) when this score increases by one unit (one point). An OR greater than 1 indicates an increase in risk; an OR less than 1 indicates a decrease in risk. Statistical analyses were conducted in SPSS 18 software.

\section{Stage 1}

Participants' Characteristics by Gender and Age. The 131 participants included 61 divers who engaged in risky diving behaviors (RT) and 70 individuals who did not (NRT). The male/female gender ratios in the two risk groups were 56:5 for RTs and 60:10 for NRTs. There was no significant difference in gender $\left(\chi^{2}=1.19\right.$, $p=.27, \mathrm{w}=0.26)$ or age, $F(1,131)=0.43, p=.83, \eta^{2}=0.13$, between the RT and NRT groups $\left(M_{\text {age }}\right.$ RT= 40.69 years, $S D=9.28$, range: $22-59 ; M_{\text {age }}$ NRT $=39.77$ years, $S D=9.44$, range: $24-70)$.

Comparison of Means by Risk Group. ANOVAs were conducted comparing by group (RT vs. NRT) on the following variables: extraversion, neuroticism, affectivity (negative and positive), and alexithymia (see Table 1). The participants in the RT group obtained higher extraversion scores than those in the NRT group, $F(1,131)=$ 
Table 1 Mean and Standard Deviation of All Variables Among RiskTakers and Non-Risk-Takers $(N=131)$

\begin{tabular}{|c|c|c|c|c|c|}
\hline \multirow[b]{2}{*}{ Factors } & \multicolumn{2}{|c|}{ RT } & \multicolumn{2}{|c|}{ NRT } & \multirow{2}{*}{$\frac{\text { Univariate }}{F}$} \\
\hline & $M$ & $S D$ & $M$ & $S D$ & \\
\hline Extraversion & 13.115 & 3.67 & 11.70 & 3.25 & $5.45^{*}$ \\
\hline Neuroticism & 9.12 & 1.24 & 8.53 & 1.52 & $5.63 *$ \\
\hline Lie & 3.82 & 4.43 & 3.74 & 4.48 & .98 \\
\hline Positive emotionality & 50.67 & 9.29 & 45.33 & 10.66 & $9.21 *$ \\
\hline Negative emotionality & 43.57 & 15.62 & 43.27 & 12.49 & .01 \\
\hline Emotion activation & 7.82 & 3.81 & 7.57 & 3.02 & .17 \\
\hline DIF & 15.02 & 5.03 & 15.51 & 5.40 & .29 \\
\hline DDF & 12.67 & 3.51 & 13.83 & 4.48 & 2.64 \\
\hline EOT & 17.30 & 4.31 & 18.77 & 4.14 & $3.97 *$ \\
\hline TAS TOT & 45.00 & 10.21 & 48.11 & 9.97 & 3.10 \\
\hline
\end{tabular}

Note. $\mathrm{RT}=$ risk-taker; $\mathrm{NRT}=$ non-risk-taker; DIF $=$ difficulty in identifying feelings; DDF $=$ difficulty in describing feelings; EOT = externally oriented thinking; TAS TOT = Toronto Alexithymia Scale Total score.

$* p<.05$ (2-tailed).

$5.45, p=.02, \eta^{2}=0.25$. The RT participants also reported more positive emotions than the NRT participants, $F(1,131)=9.21, p=.003, \eta^{2}=0.33$. Concerning the alexithymia scores, the RT group showed less externally oriented thinking than the NRT group, $F(1,131)=3.97, p=.048, \eta^{2}=0.31$.

Correlations Among Variables for Risk-Takers and Non-Risk-Takers. Correlation analyses among study variables for the RT group revealed several significant relationships. Results showed that for the RT group (a) extraversion was significantly correlated with positive affectivity, $r=.30, p<.05$; (b) neuroticism was significantly correlated with negative affectivity, $r=.34, p<.01$; (c) neuroticism was significantly associated with difficulty identifying emotions, $r=.34, p<.01$; and (d) positive affectivity was significantly and inversely correlated with difficulty describing emotions, $r=.40, p<.001$. Correlation analyses for the NRT group also yielded significant relationships: (a) neuroticism was inversely correlated with positive affectivity, $r=.30, p<.0$; (b) neuroticism was positively correlated with negative affectivity, $r=.34, p<.01$; (c) neuroticism was correlated with alexithymia (TAS-20 total score), $r=.34, p<.01$, with difficulty identifying emotions, $r=.34$, $p<.01$, and with difficulty describing emotions, $r=.34, p<.01$; (d) the Eysenck Lying scale score was negatively correlated with difficulty identifying emotions and with alexithymia (TAS-20 total score), $r=.34, p<.01$; (e) positive affectivity was negatively correlated with both difficulty identifying emotions and alexithymia (TAS-20 total score), $r=.30, p<.05$; and finally, (f) negative affectivity was positively correlated with both difficulty identifying emotions and alexithymia (TAS-20 total score), $r=.34, p<.01$. 
Factors Favoring Risk Taking in Scuba Diving. Logistic regression analyses examined the following variables from the previous analyses: extraversion, neuroticism, positive affectivity, negative affectivity, difficulty identifying emotions, difficulty describing emotions, and externally oriented thinking. The regression showed that the likelihood of manifesting risky behavior in diving increased with the positive affectivity score, $\mathrm{OR}=1.05, p=.004,95 \%$ CI $[1.01,1.09]$. Positive affectivity thus appears to be a factor favoring risk taking in scuba diving.

\section{Discussion}

The results of this study showed that scuba divers could be differentiated according to personality and psycho-affective variables based on their diving practices (i.e., RT vs. NRT).

First, members of the RT group were more extraverted and felt more positive emotions than members of the NRT group. These results align with those of previous studies showing that risk taking is linked to extraversion (Castanier, Le Scanff, \& Woodman, 2010; Freixanet, 1991). Second, positive affectivity also distinguished between two types of divers. A previous study with a smaller sample had shown that, compared with non-risk-taking subjects, risk-takers had higher rather than lower negative-emotion scores (Bonnet, Pedinielli, Romain, \& Rouan, 2003). Extraversion is a basic dimension of personality that explains an individual's tendency to experience positive affect (Tellegen \& Waller, 2008). Results from the current study are consistent with this account, as seen by the joint prevalence in this population of both the extraversion and positive affectivity factors. Moreover, other studies have shown that both extraversion and neuroticism influence risk taking.

Given the relationships between the personality dimensions and the affective dimensions, it seems reasonable to contend that positive and negative affectivities have their own specific effects (Hu, Xie, \& Li, 2013). Correlation analyses confirm this hypothesis by indicating a positive relationship between personality and affectivity and, similarly, a reciprocal link between neuroticism and negative emotions. Accordingly, the more extraverted subjects were, the more they felt positive emotions; the more emotionally unstable they were, the more they felt negative emotions and the more difficulty they had identifying their emotions. Finally, the more positive emotions subjects felt, the less difficulty they had describing their emotions.

Thus, the more emotionally unstable a subject was, the more that person felt negative emotions and the less he or she reported positive emotions. Individuals with less stability also exhibited more difficulty identifying and describing emotions. In addition, the higher the score obtained by members of the NRT group on the Lying scale, the more difficulty they had identifying emotions. Finally, the more positive emotions participants reported, the less difficulty they had identifying emotions, and the more negative affectivity participants reported, the more difficulty they had identifying emotions. These results are consistent with the established literature on positive and negative affect (Watson \& Clark, 1992). Neuroticism also was positively correlated with difficulty identifying emotions, and positive affectivity was negatively linked to difficulty describing emotions. This confirms the results of studies showing the association between neuroticism and alexithymia (Bagby, Taylor, \& Parker, 1994) and the link between extraversion and the expression of 
emotions (Gross, 1999). The high scores obtained here on the cognitive component of alexithymia also serve to underline the strong influence of extraversion as a broad dimension of personality among risk-taking subjects (Castanier, Le Scanff, \& Woodman, 2010). Our final objective was to determine the factors favoring risk taking during scuba diving. Only positive affectivity favored risk taking, which increased by 1.05 for each 1-point increase on the affectivity score. These results demonstrate the impact of the emotion variables on risk taking.

\section{Stage 2}

Participant Characteristics by Gender and Age. The 61 participants in the RT group were divided into 36 divers who took short-term risks while diving (shortterm risk-takers or STRT) and 25 divers who took long-term risks (long-term risk-takers or LTRT). The male/female gender ratios for the two groups were 33:3 for the STRT group and 23:2 for the LTRT group. There was no significant gender difference $\left(\chi^{2}=1.19, p=0.27, \mathrm{w}=0.26\right)$ or age difference, $F(1,131)=0.43, p$ $=0.83, \eta^{2}=0.13$, between the two groups $\left(M_{\text {age }}\right.$ STRT $=40.06$ years, $S D=9.95$, range: $22-59 ; M_{\text {age }}$ LTRT $=41.60$ years, $S D=8.59$, range: $\left.24-59\right)$.

Comparison of Means by Risk Group. Means were compared according to the type of risk taking (STRT vs. LTRT) on the following variables: extraversion, neuroticism, emotionality (negative and positive), and alexithymia (see Table 2).

Table 2 Mean and Standard Deviation for All Variables Among Short-Term Risk-Takers and Long-Term Risk-Takers $(N=61)$

\begin{tabular}{|c|c|c|c|c|c|}
\hline \multirow[b]{2}{*}{ Factors } & \multicolumn{2}{|c|}{ STRT } & \multicolumn{2}{|c|}{ LTRT } & \multirow{2}{*}{$\begin{array}{c}\text { Univariate } \\
\boldsymbol{F}\end{array}$} \\
\hline & $M$ & $S D$ & $M$ & $S D$ & \\
\hline Extraversion & 12.7 & 3.89 & 13.68 & 3.34 & 1.00 \\
\hline Neuroticism & 9.19 & 4.26 & 9 & 4.75 & .28 \\
\hline Lie & 3.97 & 1.36 & 3.60 & 1.04 & 1.32 \\
\hline Positive emotionality & 49.94 & 8.80 & 51.72 & 10.04 & .53 \\
\hline Negative emotionality & 45.06 & 17.67 & 41.44 & 12.11 & .78 \\
\hline Emotion activation & 8.47 & 4.27 & 6.88 & 2.83 & 2.64 \\
\hline DIF & 16.50 & 5.11 & 12.88 & 4.12 & $8.66^{* *}$ \\
\hline DDF & 13.69 & 3.22 & 11.20 & 3.45 & $8.33 * *$ \\
\hline EOT & 18.44 & 4.51 & 15.64 & 3.45 & $6.84 * *$ \\
\hline TAS TOT & 48.67 & 9.79 & 39.72 & 8.47 & $13.71 * * *$ \\
\hline
\end{tabular}

Note. STRT = short-term risk-taker; LTRT= long-term risk-taker; DDF = difficulty in describing feelings; EOT $=$ externally oriented thinking; TAS TOT $=$ Toronto Alexithymia Scale Total score.

$* p<.05$ (2-tailed).

$* * p<.01$ (2-tailed).

$* * * p<.001$ (2-tailed). 
The STRT divers scored higher than the LTRT divers on the following variables: difficulty identifying emotions, $F(1,61)=8.60, p=.005, \eta^{2}=0.59$; difficulty describing emotions, $F(1,61)=8.33, p=.005, \eta^{2}=0.59$; externally oriented thinking, $F(1,61)=6.84, p=.01, \eta^{2}=0.55$; and the total alexithymia score, $F(1$, $61)=13.71, p=.000, \eta^{2}=0.67$.

Correlations Among Variables for Short-Term and Long-Term Risk-Takers. The correlation analyses for the STRT group showed that neuroticism was significantly associated with negative emotions, $\rho=0.34, p<.01$; difficulty identifying emotions, $\rho=0.34, p<.01$; and alexithymia (TAS-20 total score), $\rho=0.30, p<.05$. The correlation analyses for the LTRT group showed that (a) extraversion was negatively correlated with negative emotions, $\rho=0.34, p<.01$, and with difficulty describing emotions, $\rho=0.34, p<.01$; and (b) positive affectivity was negatively correlated with difficulty describing emotions, $\rho=0.34, p<.01$.

Factors Favoring Short-Term Risk Taking in Scuba Diving. A logistic regression model was tested by entering the variables derived from the previous analyses: extraversion, neuroticism, positive affectivity, negative affectivity, difficulty identifying emotions, difficulty describing emotions, externally oriented thinking, and total alexithymia. The regression showed that the probability of exhibiting short-term risk-taking behavior in diving increased with alexithymia (TAS-20 total score), OR $=1.11, p=.002,95 \%$ CI $[1.04,1.18]$. Alexithymia thus appears to be a factor favoring short-term risk taking in scuba diving.

\section{Discussion}

The results of Stage 2 showed that alexithymia was a key variable of emotional functioning among the STRT participants. The two groups of participants differed on this factor, in both of its dimensions: the emotional dimension involving difficulty identifying and describing emotions, and the cognitive dimension or externally oriented thinking. Alexithymia differentiated the two types of risktakers and appears to be a factor that favors short-term risk taking. This study thus provided evidence of the importance of broad personality dimensions and affectivity, allowing us to distinguish between RT and NRT subjects. Alexithymia also enabled us to differentiate divers who knowingly seek danger from those who seek it indirectly. These results are in line with studies showing the influence of an individual's emotional functioning in risk taking, whether related to substance use (Bréjard, Pedinielli, \& Rouan, 2006) or scuba diving (Bonnet et al., 2008), as well as the role of alexithymia in high-risk sports (Woodman, Hardy, Barlow, \& Le Scanff, 2010). Broad measures of individual differences do not account for the specifics of risky activities, which are context dependent (Lo, Repin, \& Steenbarger, 2005; Martha, Sanchez, \& Freixanet, 2009). When studied in conjunction with its emotional components, and more particularly their processing, however, risk taking in so-called extreme sports seems to be supported by processes involving emotion regulation (Bonnet et al., 2003).

Consistent with the literature on this topic, the current study highlighted relationships between neuroticism and negative emotions (Eysenck, Barrett, Wilson, \& Jackson,1992) among short-term risk-taking divers, and between extraversion 
and positive emotions (Watson \& Clark, 1992) among long-term risk-taking divers. Neuroticism and extraversion are robust dimensions (Williams, 1981), and their impact operates over the long term (Kardum \& Hudek-Knezevic, 1996). Costa and McCrae (1980) showed that individual differences in these two dimensions can predict differences in negative and positive affectivities over a period of 10 years. These dimensions manifested themselves differently in our two groups of risk-taking participants. In fact, the more emotionally unstable the members of the STRT were, the more they endorsed negative emotions, and the more they had difficulty identifying their emotions. Moreover, results showed that neuroticism was the only variable linked to alexithymia for the STRT group, whereas for the LTRT group, both extraversion and positive affectivity were linked to alexithymia. Their respective relationships with the identifying and describing aspects of alexithymia (i.e., DIF for the STRT group, DDF for the LTRT group) suggest that these two types of risk taking are rooted in different individual characteristics regarding emotion experience.

While the externally oriented thinking dimension of alexithymia allowed us to differentiate RT from NRT participants, the relationships that the identification and description aspects of alexithymia had with the affect variables allowed us to differentiate the two forms of risk taking (STRT and LTRT).

\section{Conclusion}

Alexithymia was a factor contributing to short-term risk taking. In its emotional dimensions (i.e., identifying and describing emotion), alexithymia seems to be mood dependent, unlike the cognitive dimension (Fargès \& Fargès, 2002). Given that risk-taking subjects are sensitive to the emotional dimensions, their response in the face of danger might rely, for example, on what they are sensing at the moment. This reliance may be due to their initial difficulty not only in identifying and describing their current emotions but also in elaborating them. The function of the risky behavior would thus not simply be compensatory and aimed to avoid depressive affect, but would play a role in the processing of that affect. Thus, alexithymia seems to be a key variable in the emotional functioning of subjects who engage in risky behaviors.

Independently of its relationship with depression, alexithymia could constitute a preferred mode of emotion processing (Loas et al., 2000). The emotion-processing mode appears to be central to the dynamic process underlying risk taking, whether active or passive, suggesting that in cases of deficient emotional awareness, alexithymia acts as an interface in the emotion-regulating process (Zimmerman, Salamin, $\&$ Reicherts, 2008). This supports conclusions drawn in other studies demonstrating the mediating role of alexithymia between affectivity and risky behaviors (Bonnet, Bréjard, \& Pedinielli, 2013). Alexithymia would thus be at the heart of the emotionregulation process. As such, alexithymia could be helpful in further specifying this process by reflecting participants' ability to identify, describe, and express their emotions. Preventive and therapeutic interventions targeting emotion regulation, such as soliciting emotional intelligence (e.g., recognizing and responding to emotion information), or consciousness of one's own emotional experience might be interesting for clinicians' actions. They could be effective in reducing undesirable 
or dysregulated emotional experiences leading to risk-taking behaviors. More than an etiological factor, alexithymia might constitute a factor that reinforces and maintains an individual's involvement in the behavioral sphere (Thorberg et al., 2009).

\section{References}

Adès, J., Lejoyeux, M., \& Tassain, V. (1994). Sémiologie des conduites à risque. EMCPsychiatrie, 4, 37-114.

Aluja, A., Garcia, O., \& Garcia, L.F. (2002). A comparative study of Zuckerman's three structural models for personality through the NEO-PI-R, ZKPQ-III-R, EPQ-RS and Goldberg's 50-bipolar adjectives. Personality and Individual Differences, 33, 713-725. doi:10.1016/S0191-8869(01)00186-6

Auerbach, R.P., Abela, J.R.Z., \& Ho, M.H.R. (2007). Responding to symptoms of depression and anxiety: Emotion regulation, neuroticism, and engagement in risky behaviors. Behaviour Research and Therapy, 45, 2182-2191. PubMed doi:10.1016/j. brat.2006.11.002

Bagby, R.M., Taylor, G.H., \& Parker, J.D.A. (1994). The twenty-item Toronto alexithymia scale II. Convergent, discriminate, and concurrent validity. Journal of Psychosomatic Research, 38, 33-40. PubMed doi:10.1016/0022-3999(94)90006-X

Boden, B.P. (2008). Spinal injuries in sport. Neurologic Clinics, 26(1), 63-78.

Bonnet, A., Bréjard, V., \& Pedinielli, J.L. (2013). Emotional disposition and substance use: Mediating effect of alexithymia. Psychological Reports, 112, 289-302.

Bonnet, A., Fernandez, L., Piolat, A., \& Pedinielli, J.L. (2008). Emotional state changes before and after risk taking in scuba diving. Journal of Clinical Sports Psychology, 2, 25-41. doi:10.1123/jesp.2.1.25

Bonnet, A., Pedinielli, J.L., Romain, F., \& Rouan, G. (2003). Bien-être subjectif et régulation émotionnelle dans les conduites à risque. Cas de la plongée sous-marine. L囚Encéphale, 29, 88-97.

Bréjard, V., Pedinielli, J.L., \& Rouan, G. (2006). Hypothèse d'un dysfonctionnement émotionnel chez des adolescents présentant des comportements à risque: Une étude exploratoire. L区Encéphale, 32, 413-420. PubMed doi:10.1016/S0013-7006(06)76182-6

Buckner, J.D., Keough, M.E., \& Schmidt, N.B. (2007). Problematic alcohol and cannabis use among young adults: The roles of depression and discomfort and distress tolerance. Addictive Behaviors, 32, 1957-1963. PubMed doi:10.1016/j.addbeh.2006.12.019

Castanier, C., Le Scanff, C., \& Woodman, T. (2011). Mountaineering as affect regulation: The moderating role of self-regulation strategies. Anxiety, Stress, and Coping, 24(1), 75-89. PubMed doi:10.1080/10615801003774210

Castanier, C., Le Scanff, C., \& Woodman, T. (2010). Who takes risks in high-risk sports? A typological personality approach. Research Quarterly for Exercise and Sport, 81, 478-484. PubMed doi:10.1080/02701367.2010.10599709

Ciarrochi, J., Scott, G., Deane, F.P., \& Heaven, P.C.L. (2003). Relations between social and emotional competence and mental health: A construct validation study. Personality and Individual Differences, 35, 1947-1963. doi:10.1016/S0191-8869(03)00043-6

Cicchetti, D., Ackerman, B.P., \& Izard, C.E. (1995). Emotions and emotion regulation in developmental psychopathology. Development and Psychopathology, 7, 1-10. doi:10.1017/S0954579400006301

Cooper, M.L., Agocha, V.B., \& Sheldon, M.S. (2000). A motivational perspective on risky behaviors: The role of personality and affect regulatory processes. Journal of Personality, 68, 1059-1088. PubMed doi:10.1111/1467-6494.00126

Corcos, M., \& Speranza, M. (2003). Psychopathologie de l'alexithymie. In M. Corcos \& M. Speranza (Eds.), Psychothérapies (pp. 276-288). Paris: Dunod. 
Costa, P.T., \& McCrae, R.R. (1980). Influence of extraversion and neuroticism on subjective well-being: Happy and unhappy people. Journal of Personality and Social Psychology, 38, 668-678. PubMed doi:10.1037/0022-3514.38.4.668

Costa, P.T., \& McCrae, R.R. (1992). Four ways five factors are basic. Personality and Individual Differences, 13, 653-665. doi:10.1016/0191-8869(92)90236-I

Coulange, M., Metifiot-Windson, N., Desplantes, A., Barberon, B., Thomas, E., Toesca, R., . . Auffray, J.P. (2013). Epidemiology of diving accidents in the region of Marseille from 2000 to 2009. Archives des Maladies Professionnelles, 74, 549.

Cranford, J.A., Eisenberg, D., \& Serras, A.M. (2009). Substance use behaviors, mental health problems, and use of mental health services in a probability sample of college students. Addictive Behaviors, 34, 134-145. PubMed doi:10.1016/j.addbeh.2008.09.004

David, J.P., Green, P.J., Martin, R., \& Suls, J. (1997). Differential roles of neuroticism, extraversion, and event desirability for mood in daily life: An integrative model of top-down and bottom-up influences. Journal of Personality and Social Psychology, 73, 149-159. PubMed doi:10.1037/0022-3514.73.1.149

Diener, E., \& Larsen, R.J. (1993). The experience of emotional well-being. In M.L.J.M. Haviland (Ed.), Handbook of emotions (pp. 405-415). New York: Guildford Press.

Eysenck, H.J. (1967). The biological basis of personality. Springfield, IL: Charles C Thomas.

Eysenck, H.J., Barrett, P., Wilson, G., \& Jackson, C. (1992). Primary trait measurement of the 21 components of the P-E-N system. European Journal of Psychological Assessment, 8, 109-117.

Eysenck, H.J., \& Eysenck, S.B. (1971). Manuel de l'Eysenck Personality Inventory. Paris: ECPA.

Fargès, F., \& Fargès, S. (2002). Alexithymie et substances psychoactives: Revue critique de la littérature. Psychotropes, 8, 47-74. doi:10.3917/psyt.082.0047

Fave, A.D., Bassi, M., \& Massimini, F. (2003). Quality of experience and risk perception in high-altitude rock climbing. Journal of Applied Sport Psychology, 15, 82-98. doi:10.1080/10413200305402

Ferrando, P.J., \& Chico, E. (2001). The construct of sensation seeking as measured by Zuckerman's SSS-V and Arnett's AISS: A structural equation model. Personality and Individual Differences, 31, 1121-1133. doi:10.1016/S0191-8869(00)00208-7

Freixanet, M.G. (1991). Personality profile of subjects engaged in high physical risk sports. Personality and Individual Differences, 12, 1087-1093. doi:10.1016/0191-8869(91)90038$\mathrm{D}$

Freixanet, M.G. (1999). Personality profile of subjects engaged in high physical risk sports. Human Performance in Extreme Environments, 4, 11-17.

Glicksohn, J., \& Abulafia, J. (1998). Embedding sensation seeking within the big three. Personality and Individual Differences, 25, 1085-1099. doi:10.1016/S01918869(98)00096-8

Grandjean, B. (2010). Enquête nationale. Accidents de plongée sportive en scaphandre autonome. Ajaccio, France: FFESSM, Medical and Preventive Commission.

Green, M., Turner, C., Purdie, D.M., \& McClure, R. (2003). Injury related risk behaviour: A study of Australian skydivers. Journal of Science and Medicine in Sport, 6, 166-175. PubMed doi:10.1016/S1440-2440(03)80252-9

Gross, J.J. (1999). Emotion regulation: Past, present, future. Cognition and Emotion, 13, 551-573. doi:10.1080/026999399379186

Honkalampi, K., Hintikka, J., Tanskanen, A., Lehtonen, J., \& Viinamäki, H. (2000). Depression is strongly associated with alexithymia in the general population. Journal of Psychosomatic Research, 48, 99-104. PubMed doi:10.1016/S0022-3999(99)00083-5

Hu, T.Y., Xie, X., \& Li, J. (2013). Negative or positive? The effect of emotion and mood on risky driving. Transportation Research Part F: Traffic Psychology and Behaviour, 16, 29-40. doi:10.1016/j.trf.2012.08.009 
Jack, S.J., \& Ronan, K.R. (1998). Sensation seeking among high- and low-risk sports participants. Personality and Individual Differences, 25, 1063-1083. doi:10.1016/ S0191-8869(98)00081-6

Jones, G., Asghar, A., \& Llewellyn, D.J. (2007). The epidemiology of rock climbing injuries. British Journal of Sports Medicine, 42, 773-778. PubMed doi:10.1136/ bjsm.2007.037978

Kardum, I., \& Hudek-Knezevic, J. (1996). The relationship between Eysenck's personality traits, coping styles and moods. Personality and Individual Differences, 20, 341-350. doi:10.1016/0191-8869(95)00182-4

Larsen, R.J., \& Diener, E. (1985). A multitrait multimethod examination of affect structure: Hedonic level and emotional intensity. Personality and Individual Differences, 6, 631-636. doi:10.1016/0191-8869(85)90013-3

Lefèvre, B., \& Elfeki-Mhiri, S. (2015). Facteurs sociodémographiques et pratiques associées aux accidents liés à la pratique physique et sportive. Science \& Sports, 30, 126-133. doi:10.1016/j.scispo.2015.03.001

Llewellyn, D.J., \& Sanchez, X. (2008). Individual differences and risk taking in rock climbing. Psychology of Sport and Exercise, 9, 413-426. doi:10.1016/j.psychsport.2007.07.003

Llewellyn, D.J., Sanchez, X., Asghar, A., \& Jones, G. (2008). Self-efficacy, risk taking and performance in rock climbing. Personality and Individual Differences, 45, 75-81. doi:10.1016/j.paid.2008.03.001

Lo, A.W., Repin, D.V., \& Steenbarger, B.N. (2005). Fear and greed in financial markets: A clinical study of day-traders. Cognitive Neuroscientific Foundations of Economic Behavior, 95, 352-359.

Loas, G., Corcos, M., Stephan, P., Pellet, J., Bizouard, P., Venisse, J.L., . . Jeammet, P. (2001). Factorial structure of the 20-item Toronto Alexithymia Scale: Confirmatory factorial analyses in nonclinical and clinical samples. Journal of Psychosomatic Research, 50, 255-261. PubMed doi:10.1016/S0022-3999(01)00197-0

Loas, G., Otmani, O., Lecercle, C., \& Jouvent, R. (2000). Relationships between the emotional and cognitive components of alexithymia and dependency in alcoholics. Psychiatry Research, 96, 63-74. PubMed doi:10.1016/S0165-1781(00)00189-X

Luminet, O., Bagby, R.M., Wagner, H., Taylor, G.J., \& Parker, J.D.A. (1999). Relation between alexithymia and the five-factor model of personality: A facet-level analysis. Journal of Personality Assessment, 73, 345-358. PubMed doi:10.1207/ S15327752JPA7303_4

Magid, V., Colder, C.R., Stroud, L.R., Nichter, M., \& Nichter, M. (2009). Negative affect, stress, and smoking in college students: Unique associations independent of alcohol and marijuana use. Addictive Behaviors, 34, 973-975. PubMed doi:10.1016/j. addbeh.2009.05.007

Martha, C., Sanchez, X., \& Freixanet, M. (2009). Risk perception as a function of risk exposure amongst rock climbers. Psychology of Sport and Exercise, 10, 193-200. doi:10.1016/j.psychsport.2008.07.004

Merritt, C.J., \& Tharp, I.J. (2013). Personality, self-efficacy and risk-taking in parkour (free-running). Psychology of Sport and Exercise, 14, 608-611. doi:10.1016/j.psychsport.2013.03.001

Michel, G., Purper-Ouakil, D., \& Mouren-Siméoni, M.C. (2002). Prise de risque chez les jeunes: Les conduites dangereuses en véhicules motorisés. Neuropsychiatrie de l'Enfance et de l'Adolescence, 50, 583-589. doi:10.1016/S0222-9617(02)00166-6

Morgan, C., \& Stevens, C.M. (2008). Changes in perception of risk and competence among beginning scuba divers. Journal of Risk Research, 11(8), 951-966. doi:10.1080/13669870802187691

Myers, L.B. (1995). Alexithymia and repression: The role of defensiveness and trait anxiety. Personality and Individual Differences, 19, 489-492. doi:10.1016/0191-8869(95)00094$\mathrm{M}$ 
Netter, P., Hennig, J., \& Roed, I.S. (1996). Serotonin and dopamine as mediators of sensation seeking behaviour. Neuropsychobiology, 34, 155-165. PubMed doi:10.1159/000119318

Nicholson, N., Soame, E., Fenton-O'Creevy, M., \& Willman, P. (2005). Personality and domain-specific risk-taking. Journal of Risk Research, 8, 157-176. doi:10.1080/1366987032000123856

Pandey, R., \& Mandal, M.K. (1996). Eysenckian personality dimensions and alexithymia: Examining the overlap in terms of perceived autonomic arousal. Personality and Individual Differences, 20, 499-504. doi:10.1016/0191-8869(95)00214-6

Pedinielli, J-L. (1992). Psychosomatique et alexithymie. Paris: Presses Universitaires de France.

Pelissolo, A., Rolland, J.P., Perez-Diaz, F., Jouvent, R., \& Allilaire, J.F. (2007). Evaluation dimensionnelle des émotions en psychiatrie: Validation du questionnaire Emotionnalité positive et négative à 31 items (EPN-31). L区Encéphale, 33, 256-263. PubMed doi:10.1016/S0013-7006(07)92037-0

Roberti, J.W. (2004). A review of behavioral and biological correlates of sensation seeking. Journal of Research in Personality, 38, 256-279. doi:10.1016/S0092-6566(03)00067-9

Rothbart, M.K., \& Bates, J.E. (1996). Parent report in the study of temperament. Infant Behavior and Development, 19, 276. doi:10.1016/S0163-6383(96)90330-6

Sifneos, P.E. (1973). The prevalence of "alexithymic" characteristics in psychosomatic patients. Psychotherapy and Psychosomatics, 22, 255-262. PubMed doi:10.1159/000286529

Slanger, E., \& Rudestam, K.E. (1997). Motivation and disinhibition in high risk sports: Sensation seeking and self-efficacy. Journal of Research in Personality, 31, 355-374. doi:10.1006/jrpe.1997.2193

Tabibnia, G., \& Zaidel, E. (2005). Alexithymia, interhemispheric transfer, and right hemispheric specialization: A critical review. Psychotherapy and Psychosomatics, 74, 81-92. PubMed doi:10.1159/000083166

Tellegen, A., \& Waller, N.G. (2008). Exploring personality through test construction: Development of the Multidimensional Personality Questionnaire. In G.J. Boyle, G. Matthews, \& D.H. Saklofske (Eds.), The SAGE handbook of personality theory and assessment, Vol 2: Personality measurement and testing. (pp. 261-292). Thousand Oaks, CA: Sage.

Thorberg, F.A., Young, R.M., Sullivan, K.A., \& Lyvers, M. (2009). Alexithymia and alcohol use disorders: A critical review. Addictive Behaviors, 34, 237-245. PubMed doi:10.1016/j.addbeh.2008.10.016

Tok, S. (2011). The Big Five personality traits and risky sport participation. Social Behavior and Personality, 39, 1105-1112. doi:10.2224/sbp.2011.39.8.1105

Watson, D., \& Clark, L.A. (1984). Negative affectivity: The disposition to experience aversive emotional states. Psychological Bulletin, 96, 465-490. PubMed doi:10.1037/00332909.96.3.465

Watson, D., \& Clark, L.A. (1992). On traits and temperaments: General and specific factors of emotional experience and their relation to the five-factor model. Journal of Personality, 60(2), 441-476. PubMed doi:10.1111/j.1467-6494.1992.tb00980.x

Watson, D., Clark, L.A., Weber, K., Assenheimer, J.S., Strauss, M.E., \& McCormick, R.A. (1995). Testing a tripartite model: II. Exploring the symptom structure of anxiety and depression in student, adult, and patient samples. Journal of Abnormal Psychology, 104, 15-25. PubMed doi:10.1037/0021-843X.104.1.15

Williams, D.G. (1981). Personality and mood: State-trait relationships. Personality and Individual Differences, 2, 303-309. doi:10.1016/0191-8869(81)90085-4

Wise, T.N., Mann, L.S., \& Shay, L. (1992). Alexithymia and the five-factor model of personality. Comprehensive Psychiatry, 33, 147-151. PubMed doi:10.1016/0010440X(92)90023-J 
Woodman, T., Cazenave, N., \& Le Scanff, C. (2008). Skydiving as emotion regulation: The rise and fall of anxiety is moderated by alexithymia. Journal of Sport \& Exercise Psychology, 30, 424-433. PubMed doi:10.1123/jsep.30.3.424

Woodman, T., Hardy, L., Barlow, M., \& Le Scanff, C. (2010). Motives for participation in prolonged engagement high-risk sports: An agentic emotion regulation perspective. Psychology of Sport and Exercise, 11, 345-352. doi:10.1016/j.psychsport.2010.04.002

Zimmermann, G., Rossier, J., Stadelhofen, M. de, \& Gaillard, F. (2005). Alexithymia assessment and relations with dimensions of personality. European Journal of Psychological Assessment, 21, 23-33. doi:10.1027/1015-5759.21.1.23

Zimmermann, G., Salamin, V., \& Reicherts, M. (2008). L'alexithymie aujourd'hui: Essai d'articulation avec les conceptions contemporaines des émotions et de la personnalité. Psychologie Française, 53, 115-128. doi:10.1016/j.psfr.2007.10.003

Zuckerman, M. (1984). Sensation seeking: A comparative approach to a human trait. Behavioral and Brain Sciences, 7, 413-471. doi:10.1017/S0140525X00018938

Zuckerman, M. (2007). Sensation seeking and risky behavior. Washington, DC: APA. 
Copyright of Journal of Clinical Sport Psychology is the property of Human Kinetics Publishers, Inc. and its content may not be copied or emailed to multiple sites or posted to a listserv without the copyright holder's express written permission. However, users may print, download, or email articles for individual use. 